\title{
Characterization of Chinese Hamsters by Metabolic Balance, Glucose Tolerance and Insulin Secretion
}

\author{
George C. Gerritsen and Margaret C. Blanks \\ Diabetes and Atherosclerosis Research, The Upjohn Company, Kalamazoo, Michigan, USA
}

\begin{abstract}
Summary. Lack of obesity in the hyperphagic Chinese hamster is due to a normal caloric retention. This is related to a greater loss of carbohydrate calories via urine and feces in hyperphagic animals and a reduced absorption of dietary fat. - Various types of glucosuric animals were not adequately characterized by food consumption, blood sugar, quantitated glucosuria and blood sugar or plasma insulin levels after a glucose load. Plasma insulin.
\end{abstract}

as well as blood sugar levels appeared to be influenced by stress. Overnight food deprivation followed by refeeding may be a useful technique to evaluate maximal insulin secretion in vivo.

Key words: Diabetes, Chinese hamster, hyperphagia, metabolic balance, glucosuria, blood sugar, plasma insulin, glucose tolerance, stress.
There is considerable evidence for heterogeneity of diabetes in both man [1, 2, 3, 4] and Chinese hamsters [5, 6]. In addition, phenotypic expression due to a similar genotype can vary considerably in man [7, 8], Chinese hamsters [6] and mice [9].

It has been observed that Chinese hamsters from individual and highly inbred sublines ( $>15$ generations of continuous brother-sister mating) can have highly variable phenotypes and clinical courses ranging from aglucosuria to marked glucosuria accompanied by ketonuria. Further, it has been observed that Chinese hamsters which repeatedly have maximal 4 - Testape ${ }^{\circledR}$ tests may have fasting blood sugar levels from 138 to $382 \mathrm{mg} \%$ [6]. Studies have been done in an attempt to characterize some of these phenotypes by blood sugar and plasma insulin levels under various conditions. Since diabetic Chinese hamsters are hyperphagic but do not gain weight, metabolic balance studies were done in an attempt to understand this observation and to characterize further the diabetic syndrome(s) in this animal.

\section{Methods}

Various types of Chinese hamsters studied are defined in Table 1. All animals were maintained on Purina Mouse Breeder Chow, ad libitum, housed individually, and tested for glucosuria; if glucosuric, they were also tested for ketonuria biweekly from 15 days of age until used as previously described $[5,6]$. The updated age at onset versus date of birth computer-generated plots are as previously described [10] and definitions are as shown in Figs. 2 and 3.

In the metabolic balance studies, animals were given oral glucose tolerance test, placed in metabolism cages and acclimatized for one week prior to food consumption measurements and daily collection of urine and fecal materials. Urine volume was recorded, glucose concentrations measured and $24 \mathrm{~h}$ glucose excretion calculated as previously described [5]. Calories lost via the urine of glucosuric animals were calculated by multiplying $g$ of glucose lost per $24 \mathrm{hrs}$ by a factor of 4.0. Daily fecal collections were weighed and the week's collection for an individual animal pooled and dried to a constant weight under vacuum. The weekly collections were ground and aliquots used for determination of total lipid [11], protein [12, 13], crude fiber [14] and ash. Carbohydrate content was determined from the difference between feces weight and the four estimated components. Total calories lost via the feces were determined by multiplying $g$

Table 1. Definitions of Chinese hamsters ${ }^{\mathbf{a}}$

\begin{tabular}{|c|c|c|}
\hline $\begin{array}{l}\text { Stage } \\
\text { Inbreeding } \\
\mathbf{F}>\end{array}$ & Туре & Definition \\
\hline 10 & Nondiabetic & $\begin{aligned}= & \text { No positive Testape }{ }^{\circledR} \text { results, } \\
& \text { no diabetic relatives for }>8 \\
& \text { inbred generations }\end{aligned}$ \\
\hline 15 & Aglucosuric & $=\begin{array}{l}\text { No positive Testape }{ }^{\oplus} \text { but } \\
\text { diabetic siblings }\end{array}$ \\
\hline 10 & Trace & $=$ Intermittant $1+$ Testape \\
\hline 8 & Remission & $\begin{array}{l}=\text { Remission from consistent } 4+ \\
\text { Testape }{ }^{\circledR} \text { for at least } 4 \text { months } \\
\text { to consistent aglucosuria for } \\
\text { at least } 4 \text { months prior to } \\
\text { study }\end{array}$ \\
\hline 8 & $\begin{array}{l}\text { Erratic } \\
\text { Glucosuric }\end{array}$ & $\begin{array}{l}=\text { Erratic Testape values from } \\
\text { negative to } 4+\end{array}$ \\
\hline 10 & $\begin{array}{l}\text { Newly } \\
\text { diagnosed } \\
\text { Diabetic }\end{array}$ & $=4+$ Testape ${ }^{\circledR}<1$ month \\
\hline 10 & Diabetic & $\begin{array}{l}=\text { Consistent } 4+\text { Testape }{ }^{\circledR} \text { for } 4 \\
\text { months prior to and during } \\
\text { period of study }\end{array}$ \\
\hline 10 & Ketonuric & $\begin{array}{l}=\text { Consistent Ketostix }{ }^{\oplus} \text { rating } \\
\text { of "large" for } 2 \text { months prior } \\
\text { to and during study }\end{array}$ \\
\hline
\end{tabular}

a All animals were approximately one year of age at time of study except newly diagnosed which were $<5$ months. 
of lipid by 9.0 , protein by 4.0 and carbohydrate by 4.0 . Similar determinations and calculations were done on the feed to provide an accurate estimate of caloric intake. Protein was $16.8 \%$, fat $11.3 \%$, fiber $2.9 \%$, ash $6.0 \%$, and carbohydrate $63 \%$. Calories retained by the animals were calculated from the difference between calories consumed and calories lost via the feces and urine.

Glucose tolerance tests before and after the metabolic balance study were done as previously described [5]. In subsequent studies on a variety of phenotypes blood sugar and plasma insulin were measured after an oral glucose load $(1.5 \mathrm{~g} / \mathrm{kg})$. Animals were deprived of food overnight $(18 \mathrm{~h})$, a $0 \mathrm{~h}$ blood sample taken via the orbital sinus [15], and in most cases, one additional blood sample taken at either $15,30,60$ or 120 min after the glucose load. Blood sugar was measured as previously described [5] and plasma insulin measured by an ultramicro technique [16]. The maximum amount of blood withdrawn from any animal on a given day was $0.25 \mathrm{ml}$. tonurics are significantly higher than trace or nondiabetics.

Mean daily food consumption for all types remained fairly constant for the four week observation. period and was consistent for a given animal (Table 3). However, variation among animals within a group was quite large, especially in diabetics and glucosurics. Daily food consumption varied from: 3.1 to $3.9 \mathrm{~g} / \mathrm{d}$ for nondiabetics, 3.5 to 4.0 for "trace", 2.2 to 7.6 for diabetics and 3.7 to 8.0 for ketonuries. Body weights for all animals remained constant during the study and no correlation between body weight and food consumption was found. Coefficients were $r=0.55$ and 0.2 respectively for ketonurics and diabetics. Diabetics and ketonurics ate significantly more than either "trace" or nondiabetics. Daily food consumption was not different between "trace" and nondiabetics or between ketonurics and diabetics.

Daily urine sugar loss was quite consistent during the four week observation period but was not significantly different between ketonurics and diabetics

Table 2. Characteristics of Chinese hamsters used for metabolic balance studies $(M e a n \pm S E M)$

\begin{tabular}{|c|c|c|c|c|c|c|}
\hline \multirow{3}{*}{ Тype } & \multirow{3}{*}{ No. } & \multirow{3}{*}{$\begin{array}{l}\text { Body } \\
\text { Wt. (g) }\end{array}$} & \multirow{3}{*}{$\begin{array}{l}\text { Blood } \\
\text { Sugara } \\
\text { (mg \%) }\end{array}$} & \multicolumn{3}{|c|}{ Months \pm S.E. ${ }^{a}$} \\
\hline & & & & \multirow[t]{2}{*}{ Age } & \multicolumn{2}{|c|}{ Age at Onset } \\
\hline & & & & & Glucosuria & Ketonuria \\
\hline Nondiabetic & 6 & $32.8 \pm 3.5$ & $96 \pm 1.6$ & 12. & - & - \\
\hline Trace & 5 & $36.7 \pm 0.6$ & $110 \pm 3.1$ & 12.0 & $3.2 \pm 1.0$ & - \\
\hline Diabetic. & 10 & $33.8 \pm 1.5$ & $359 \pm 28$ & $12.5 \pm 0.7$ & $2.4 \pm 0.2$ & - \\
\hline Ketonuric & 8 & $31.2 \pm 2.0$ & $329 \pm 28$ & $12.3 \pm 0.4$ & $1.5 \pm 0.3$ & $6.3 \pm 1.0$ \\
\hline
\end{tabular}

a Nonfasting

In a crossover study, blood sugar [5] and plasma insulin [16] were measured after a $1.5 \mathrm{~g} / \mathrm{kg}$ oral glucose load in nondiabetic hamsters deprived of food for $18 \mathrm{hrs}$. In these studies, half the animals were bled serially at 0,15 and $30 \mathrm{~min}$ after glucose. The other half bled at 0 time on the first week, $15 \mathrm{~min}$ on the second, and $30 \mathrm{~min}$ on the third. Then the procedure was reversed.

In an attempt to measure $\beta$-cell secretory response, various types of animals were deprived of food overnight $(18 \mathrm{~h})$, allowed food ad libitum for $20 \mathrm{~min}$ and one blood sample removed [15] for blood sugar and plasma insulin [17]. Preliminary studies indicated that 20 min gave a maximal blood sugar and insulin response to refeeding. Statistical analyses were all done by Wilcoxin test [18].

\section{Results}

Table 2 shows basic characteristics of the phenotypes studied in the metabolic balance study. Body weight, age and age at onset of glucosuria are similar. Nonfasting blood sugar levels of diabetios and ke-
Table 3. Daily food consumption ( $g /$ day) of Chinese hamsters for four week period (mean $\pm S E M$ )

\begin{tabular}{lrllll}
\hline \multirow{2}{*}{ Type } & No. Weeks & \multicolumn{3}{l}{} \\
\cline { 3 - 6 } & & 1 & 2 & 3 & 4 \\
\hline Nondiab. & 6 & $3.6 \pm 0.2$ & $3.5 \pm 0.1$ & $3.7 \pm 0.2$ & $3.6 \pm 0.2$ \\
Trace & 5 & $3.7 \pm 0.1$ & $3.7 \pm 0.1$ & $4.1 \pm 0.1$ & $3.9 \pm 0.2$ \\
Diab. & 10 & $4.6 \pm 0.5$ & $5.1 \pm 0.5$ & $5.1 \pm 0.4$ & $4.7 \pm 0.3$ \\
Ket. & 8 & $6.0 \pm 0.6$ & $6.0 \pm 0.5$ & $5.8 \pm 0.6$ & $5.6 \pm 0.4^{a}$ \\
\hline
\end{tabular}

a Mean of 7 animals

(Table 4). It should be pointed out that each diabetic tested $4+$ by Testape ${ }^{\circledR}$ each day, and each ketonuric tested "large" by Ketostix ${ }^{\circledR}$. However, variation among animals was large and probably was responsible for lack of statistical significance. Glucosuria varied from 186 to $1,186 \mathrm{mg} / 24 \mathrm{hrs}$ in diabetics and from 443 to $1,171 \mathrm{mg} / 24 \mathrm{~h}$ in ketonurics. Correlations between food consumption and glucosuria were not very impressive $(r=0.43$ and 0.74 respectively for ketonurics and glucosurics).

Data from the metabolic balance study are summarized in Table 5. Since data from nondiabetic and "trace" animals were the same, their data are pooled 
and presented under the nonglucosurics. Total caloric intake was significantly higher for diabetics compared with nonglucosurics due to increased uptake of calories from dietary carbohydrate. Calories absorbed from protein and lipid were not different. Since calories lost via the urine and feces were significantly greater in the diabetic and ketonuric groups, net caloric retention was similar in all groups. It is interesting to note that per cent of lipid absorbed from the diet is significantly reduced in the diabetic and ketonuric groups.

Table 4. Daity urine sugar excretion ( $\mathrm{mg} / 24 \mathrm{hr}$ ) of diabetics for the four week period (mean $\pm S E M$ )

\begin{tabular}{|c|c|c|c|c|c|}
\hline \multirow{2}{*}{ Type } & \multirow{2}{*}{ No. } & \multicolumn{4}{|l|}{ Weeks } \\
\hline & & 1 & 2 & 3 & 4 \\
\hline Diab. & 10 & $729 \pm 115$ & $645 \pm 117$ & $693 \pm 120$ & $835 \pm 104$ \\
\hline Ketotic & 8 & $905 \pm 86$ & $861 \pm 66$ & $1000 \pm 125^{\mathrm{a}}$ & $1012 \pm 95^{\mathrm{a}}$ \\
\hline
\end{tabular}

a Mean of 7 animals curves after an oral glucose load from some of the phenotypes in the population represented in Fig. 2, are shown in Fig. 4. All the phenotypes represented have reproducible abnormal glucose tolerance compared with genetic nondiabetics. Most of these animals were bled at 0 time and one other point to permit plasma insulin measurement presented in Table 6 . The plasma insulin levels in "trace", "remission" and diabetics do not show clear-cut deviations from the nondiabetic levels; however, in the case of the ketonuries, their levels at $15,30,60$ and $120 \mathrm{~min}$ are significantly lower than either their own $0 \mathrm{~h}$ level or the corresponding nondiabetic levels.

Highly inbred aglucosuric hamsters with diabetic siblings have abnormal glucose tolerance (Fig. 5). The experimental procedure was similar to that used for the studies presented in Fig. 4.

Comparison of effects of oral glucose loading on blood sugar and plasma insulin of the same nondiabetic animals bled once or serially are presented in Figs.

Table 5. Summary of caloric balance of Chinese hamsters

\begin{tabular}{|c|c|c|c|c|c|c|c|c|}
\hline \multirow{3}{*}{ Number Animals } & \multirow{2}{*}{\multicolumn{2}{|c|}{$\begin{array}{c}\text { Non Glueosuric } \\
\overline{\mathrm{X}} \pm \mathrm{SEM} \\
12^{\mathrm{a}}\end{array}$}} & \multirow{2}{*}{\multicolumn{2}{|c|}{$\begin{array}{c}\text { Diabetic } \\
\overline{\bar{X}} \pm \text { SEM } \\
9^{\mathrm{a}}\end{array}$}} & \multirow{2}{*}{\multicolumn{2}{|c|}{$\begin{array}{c}\text { Ketonuric } \\
\overline{\mathrm{X}} \pm \mathrm{SEM} \\
7_{\mathrm{a}} \\
\end{array}$}} & \multicolumn{2}{|c|}{ Statistical Comparisons ${ }^{b}$} \\
\hline & & & & & & & \multirow{2}{*}{$\frac{\text { NG vs Diab. }}{p=0.01}$} & \multirow{2}{*}{$\frac{\text { Diab. vs Ketonuric }}{\text { ns }}$} \\
\hline & 14.90 & 0.31 & 19.09 & 1.68 & 22.65 & 1.98 & & \\
\hline Cal. CHO Absorbed & 7.62 & 0.18 & 9.77 & 0.89 & 12.12 & 1.26 & $p=0.05$ & ns \\
\hline Cal. Protein Absorbed & 1.95 & 0.06 & 2.41 & 0.21 & 2.78 & 0.26 & ns & ns \\
\hline Cal. Lipid Absorbed & 3.64 & 0.08 & 3.63 & 0.22 & 3.81 & 0.22 & $\mathrm{~ns}$ & ns \\
\hline Cal. CHO Excreted (urine) & 0.01 & 0.00 & 2.80 & 0.36 & 3.64 & 0.35 & $p<0.001$ & ns \\
\hline Total cal excreted (Feces) & 1.68 & 0.09 & 3.28 & 0.28 & 3.94 & 0.38 & $p<0.001$ & ns \\
\hline Cal. Retained & 13.22 & 0.29 & 13.01 & 0.96 & 15.07 & 1.38 & ns & ns \\
\hline Body Wt. Change & +0.58 & 0.30 & +0.31 & 0.26 & +0.19 & 0.86 & $\mathrm{~ns}$ & ns \\
\hline$\%$ CHO Absorbed & 91.71 & 0.64 & 92.21 & 1.20 & 94.21 & 1.86 & ns & ns \\
\hline$\%$ Protein Absorbed & 80.91 & 1.29 & 79.22 & 1.25 & 77.73 & 1.45 & $\mathrm{~ns}$ & ns \\
\hline$\%$ Lipid Absorbed & 87.28 & 1.05 & 68.30 & 3.86 & 63.10 & 6.39 & $p<0.001$ & ns \\
\hline
\end{tabular}

a Number of animals

b Wilcoxin test (18)

Blood sugar levels after an oral glucose load were superimposable for diabetics and ketonurics following the metabolic study (Fig. 1). The curves were significantly elevated compared with the "trace" and nondiabeties. The curves for "trace" and nondiabetics were not different. During the first test (not shown) curves for ketonurics, diabetics and nondiabetics were the same as shown in Fig. 1, but the thirty min blood sugar level for the "trace" animals was significantly higher than that of the nondiabetics; however, this observation was not repeatable on the second test.

Fig. 2 shows the updated result on age at onset of glucosuria versus birth date. As previously reported $[10,6]$, onset time has remained constant since the vast majority of animals have an onset time of glucosuria of less than six months. Although onset of glucosuria appears fairly uniform, onset of ketonuria has remained variable regardless of stage of inbreeding (Fig. 3).

Although the data in Fig. 2 suggest homogeneity of phenotype, this is not the case [6]. Blood sugar

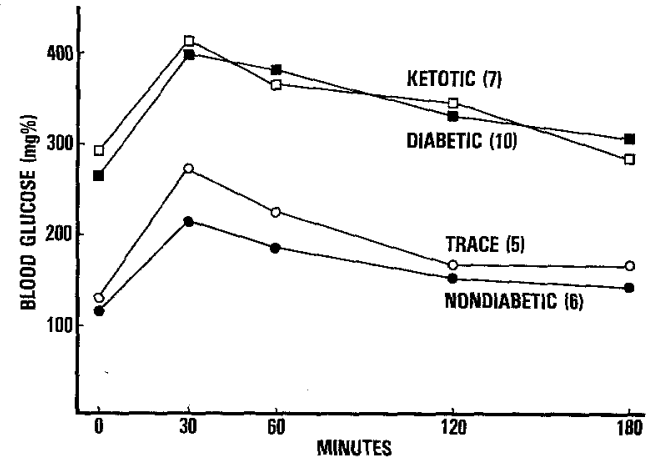

Fig. 1. Oral glucose tolerance test on Chinese hamsters after completion of metabolism study

6 and 7. Serial bleeding significantly elevated blood sugar and reduced plasma insulin in these animals.

The preliminary results presented in Table 7 suggest that the animals, deprived of food overnight and refed for $20 \mathrm{~min}$, have abnormal responses compared with nondiabetic controls. 


\section{Discussion}

The metabolic balance data suggest that the hyperphagic diabetic Chinese hamster does not gain weight or become obese because the net caloric retention is similar to the nondiabetics. The diabetic consumes more and absorbs more calories as carbohydrate than nondiabeties but this appears to be diabetic Chinese hamster. It is difficult to explain the apparent discrepancy since methodology was so different. Glucose uptake was studied by gut loops in situ [20] or in vitro [19] in alloxan-diabetic rats, and in vivo in man by following its disappearance from the gut through tubes passed into the intestine over a $4 \mathrm{~h}$ period [21]. It should be pointed out that in the metabolic balance studies in the Chinese hamsters,

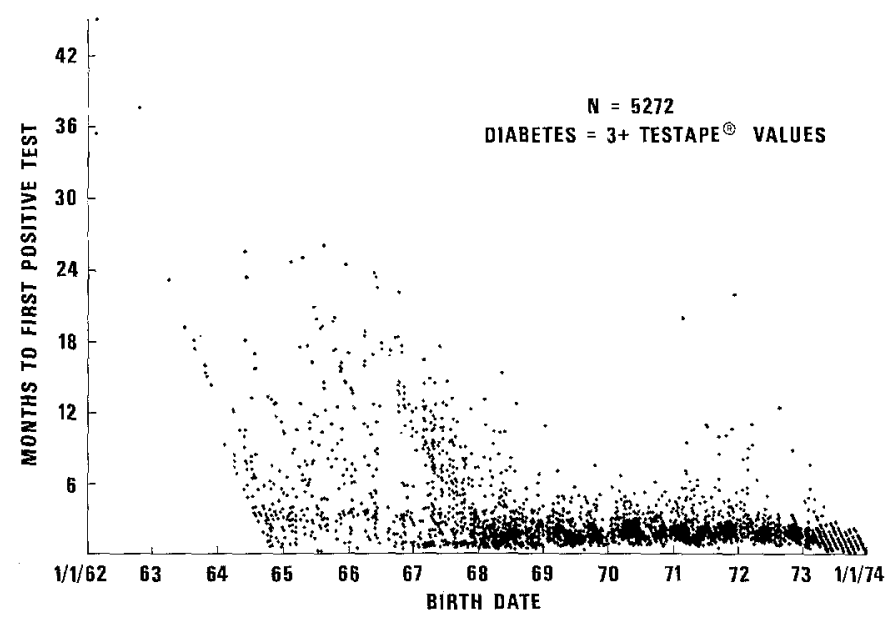

Fig. 2. Age at onset of glucosuria vs birthdate of Chinese hamsters in the Upjohn colony

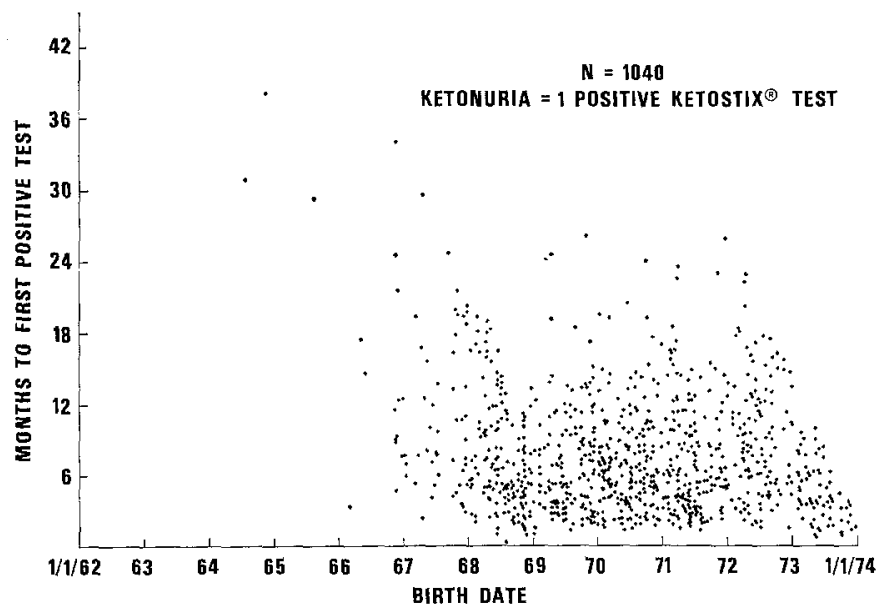

Fig. 3. Age at onset of ketonuria vs birthdate of Chinese hamsters in the Upjohn colony

compensated by calories lost via the urine and feces. Another factor which appeared to be important was that calories absorbed as fat were similar in all groups. This means that per cent of dietary fat absorbed by diabetics was less. It is generally agreed that carbohydrate absorption is enhanced in experimentally induced diabetic animals $[19,20]$ and one study in six insulin-dependent humans also suggested enhanced absorption of glucose [21]. These data appear to be contradictory to the findings of similar carbohydrate absorption in the spontaneously diabetic and non- continuous $24 \mathrm{~h}$ food consumption was measured while studies suggesting enhanced glucose uptake in rats and man measured acute glucose dispensation. Reduced dietary fat absorption related to diabetes in man has been well documented [22] and it agrees with reduced fat absorption in Chinese hamsters.

However, a recent study suggests that uptake of tracer doses of ${ }^{14} \mathrm{C}$ labelled trioleate or oleic acid was enhanced in diabetic Chinese hamsters [23]. It should. be pointed out that the apparent discrepancy in these findings on diabetic Chinese hamsters may be 
due to methodology difference, since in the oleic acid uptake studies, tracer amounts were administered to animals fasted for $24 \mathrm{~h}$, rather than incorporated into the diet.

These metabolic studies have helped us to understand the lack of obesity in the hyperphagic Chinese hamster. However, they have not supplied us with additional information regarding metabolic differences between glycosuric diabetics and ketonuric diabetics, or between "trace" and genetically nondiabetic hamsters. In part, this may be due to the process

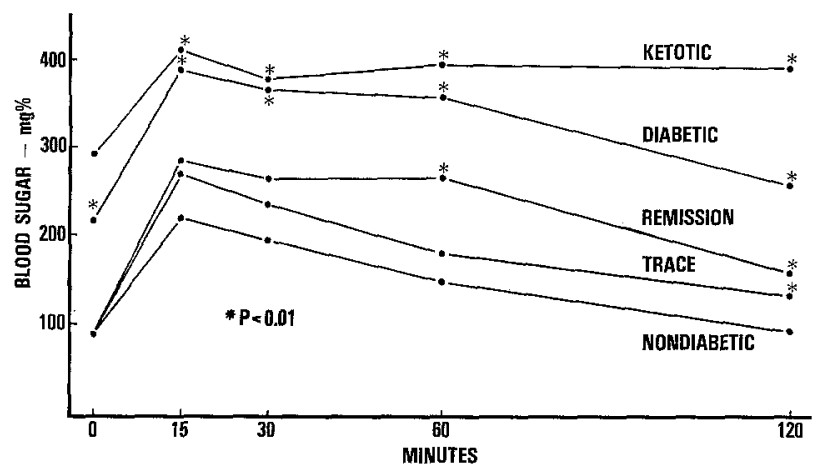

Fig. 4. Oral glucose tolerance on Chinese hamsters with various phenotypes food consumption, relative state of fasting or nonfasting, insulin secretion, hepatic glucose output which is elevated in diabetic Chinese hamsters [24], blood sugar levels per se, and renal threshold. As previously pointed out [6], but still very pertinent, blood sugar as well as semiquantitative tests for glucosuria may be so far removed from the basic genetic lesion(s) and of little use for characterization of various diabetic phenotypes. If it is necessary to make distinctions between various Chinese hamster phenotypes, in some cases it may have to be done on the basis of quantitative $24 \mathrm{~h}$ glucosuria.

The updated data on the age of onset show that the onset of glucosuria is still early, less than 6 months, and this again points to the genetic liability for diabetes and early onset. However, onset of ketonuria has remained variable suggesting that ketonuria may be influenced to a greater degree by environment than glucosuria in the diabetic Chinese hamster.

As in man [25], it does not appear that glucose tolerance test or insulin secretion after a glucose load is an adequate means for classification of diabetes. Glucose tolerance will distinguish between genetically nondiabetic animals and "trace" animals that have shown some degree of glucosuria. However, blood sugar curves or plasma insulin levels after a glucose load do not show clear differences between the various

Table 6. Plasma insulin levels in fasted Chinese hamsters after a glucose load (1.5 g/kg, oral) (mean $\pm S E M)$

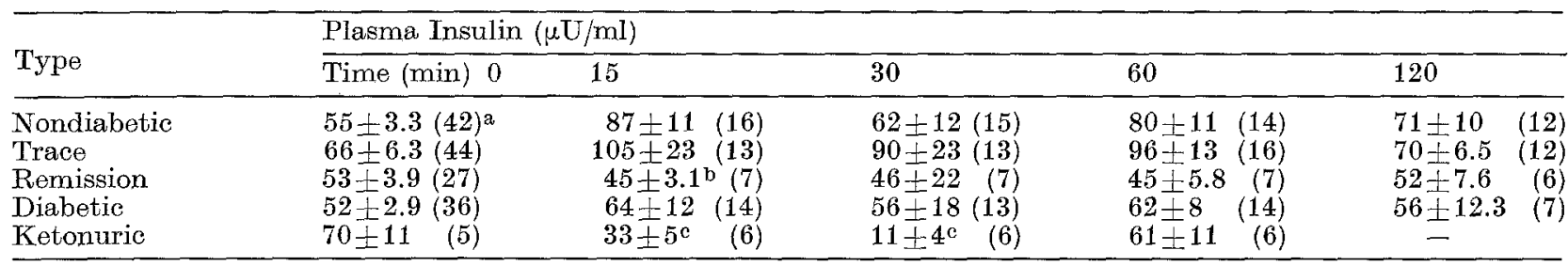

$$
\begin{aligned}
& \mathrm{a}()=\text { No. Animals/Point } \\
& \mathrm{b}=p<0.05 \\
& \mathrm{c}=p<0.001
\end{aligned}
$$

used to select animals for study. They were selected and arbitrarily defined on the basis of Testape ${ }^{\circledR}$ and Ketostix ${ }^{\circledR}$ tests. Obviously, this process was not sufficiently selective since blood sugars, food consumption and urine glucose excreted $/ 24 \mathrm{~h}$ were not uniform within a group or significantly different between diabetics and ketonurics. Further, values between the two types overlapped. It is tempting to speculate that if hamsters were selected on the basis of high or low blood sugar, food consumption and glucosuria, then it might be possible to demonstrate additional metabolic differences between animals now classified as ketonurics and diabetics. If this kind of selection process were used, it might also be possible to group diabetios with consistent $4+$ Testape ${ }^{\circledR}$ values into subclasses according to blood sugar, food consumption and $24 \mathrm{~h}$ urine glucose excretion. The degree of glacosuria is difficult to evaluate, but is probably influenced by a number of factors such as milder glucosuric types. Nonetheless, it is interesting to note that aglucosuric animals from highly inbred sublines that have diabetic siblings do have abnormal glucose tolerance. It has been postulated, on the basis of genetic homozygosity, that these aglucosurics should have a diabetic genotype [6]. The observation that these animals have abnormal glucose tolerance supports this postulation. Further, abnormal glucose tolerance in these aglucosurics has been confirmed and decreased responsiveness of their perfused pancreas to glucose has also been demonstrated [26]. It is tempting to speculate that this pancreatic lesion is related to a genetic defect which, for some reason, is not expressed as spontaneous glucosuria. Whatever the factors are that maintain these "genetic diabetics" aglucosuric may be of tremendous importance.

It appears that the Chinese hamster defined as aglucosuric is similar to the human defined as latent or chemical diabetic [27]. 
The observation that "trace" animals used in the metabolic study could not be distinguished from nondiabetics by glucose tolerance test with serial bleedings suggests that stress influenced blood sugar and plasma insulin levels. This conclusion is supported by the subsequent studies where a maximum of two blood samples was taken after the glucose load and "trace" animals were found to be abnormal. Fowever, even in that system, stress seemed to be involved to

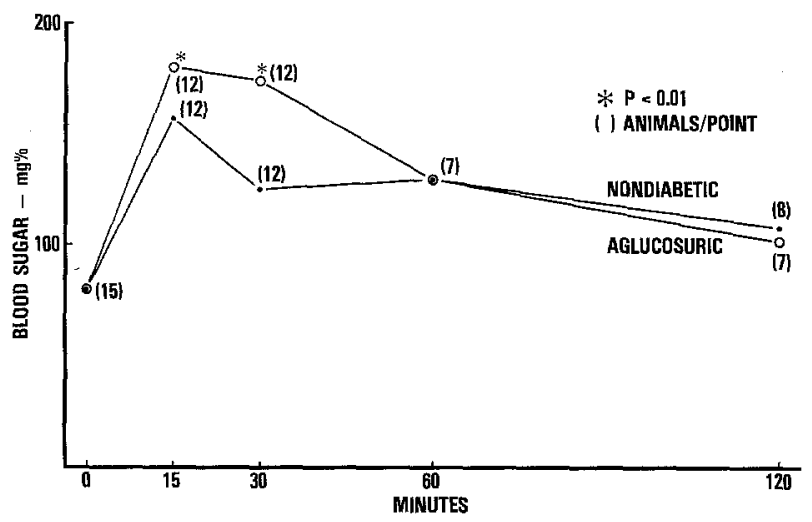

Fig. 5. Oral glucose tolerance of aglucosuric Chinese hamsters from inbred, diabetic-producing sublines

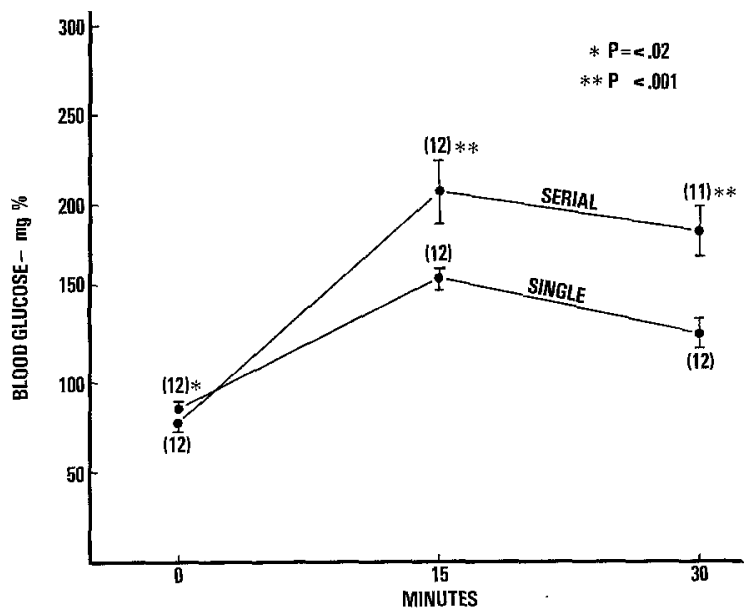

Fig. 6. Comparison of serial bleeding with single bleeding times on blood sugar after a glucose load in nondiabetic Chinese hamsters

some degree since the plasma insulin data do not show clear patterns. The effect of stress was even more pronounced in the experiments on single versus serial bleeding procedures in nondiabetics. Since the Chinese hamster is a very sensitive animal, it seems likely that epinephrine secretion is involved. Inhibition of insulin secretion by epinephrine is well known [28] and documented in a number of systems.

Because of the problem of measuring insulin responses in various types of Chinese hamsters food withdrawal followed by refeeding may be potentially useful. The preliminary data suggest that this procedure may be useful to evaluate maximal insulin secretions in vivo, since it yields the highest plasma insulin values reported in nondiabetic Chinese ham. sters. Other phenotypes had higher blood sugar and lower plasma insulin levels. The numbers were small and variation quite high so it was not possible to differentiate between defined abnormal phenotypes. However, it may be of potential value in classification.

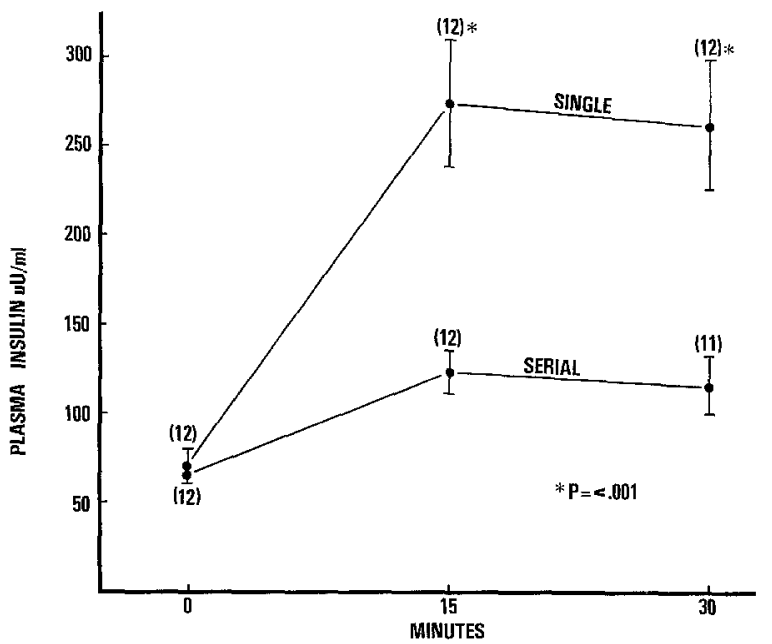

Fig. 7. Comparison of serial bleeding with single bleeding times on plasma insulin after a glucose load in nondiabetic Chinese hamsters

Table 7. Blood sugar and plasma insulin levels of food deprived, refed chinese hamsters (mean $\pm S E M$ )

\begin{tabular}{lllll}
\hline Type & No. $\begin{array}{l}\text { Blood } \\
\text { sugar }\end{array}$ & $\begin{array}{l}\text { Plasma } \\
\text { insulin }\end{array}$ & P.I./B.S. \\
\hline Nondiabetic & 4 & $148 \pm 6^{\mathrm{b}}$ & $544 \pm 45^{\mathrm{b}}$ & $3.7 \pm 0.3^{\mathrm{b}}$ \\
Newly Diagnosed & & & & \\
Diabetics & 6 & $208 \pm 13$ & $288 \pm 64$ & $1.5 \pm 0.4$ \\
Recessive & 9 & $184 \pm 27$ & $165 \pm 60$ & $1.0 \pm 0.4$ \\
Erratic & 5 & $274 \pm 28$ & $132 \pm 42$ & $0.5 \pm 0.2$ \\
Diabetic & 5 & $292 \pm 24$ & $282 \pm 64$ & $1.0 \pm 0.2$ \\
Ketonuric & 5 & $366 \pm 17$ & $136 \pm 74$ & $0.4 \pm 0.2$ \\
\hline
\end{tabular}

a Fasted overnight, refed for 20 min prior to bleeding b Non-diabetic vs. all other groups, $P<0.01$

systems, but needs to be standardized. For example, 20 min was the time at which blood sugar and insulin peaked in genetic nondiabetics but it may not be the time at which these parameters peak in other genotypes. Further, food consumption was not standardized during the $20 \mathrm{~min}$ refeeding period. It appears that this approach should be tempered with caution, since as previously mentioned, blood sugar and perhaps also plasma insulin may be far removed from the genetic lesions of diabetes and influenced by many factors not directly related to the etiology of diabetes. It reems reasonable to continue to look for end points which are more closely related to the genetic lesions of diabetes and its pathogenesis. 
In conclusion, it appears that hyperphagia in the spontaneously diabetic Chinese hamster does not result in obesity since excess calories absorbed as carbohydrate are excreted via the urine and feces. In addition, lack of obesity may be related to a significant reduction in dietary fat absorption.

Further, it is difficult to characterize completely diabetes in the Chinese hamster by food consumption, blood sugar, plasma insulin or blood sugar and plasma insulin responses to an oral glucose load.

Acknowledgement. The authors gratefully acknowledge the preparation of the computer-generated plots of onset vs birthdate by Mrs. F.L. Schmidt, Mrs. E.S. Cerda, and Mr. L.G. Leslie.

\section{References}

1. Rimoin, D.L.: Ethnic variability in glucose tolerance and insulin secretion. Arch. intern. Med. 124, 695-700 (1969)

2. Prosnitz, L.R., Mandell, G.L.: Diabetes mellitus among Navajo and Hopi Indians: the lack of vascular complications. Amer. J. med. Sci. 253, 700 (1967)

3. Bennett, P.H., Burch, T.A., Miller, M.: Diabetes mellitus in American (Pima) Indians. Lancet 1971 II, $125-128$

4. Köbberling, J.: Studies on the genetic heterogeneity of diabetes mellitus. Diabetologia 7, 46-49 (1971)

5. Gerritsen, G.C., Dulin, W.E.: Characterization of diabetes in the Chinese hamster. Diabetologia 3, 74$84(1967)$

6. Dulin, W.F., Gerritsen, G.C.: Interaction of genetics and environment on diabetes in the Chinese hamster as compared with human and other diabetic animal species. Acta diabet. lat. 9, Suppl. 1, 48-84 (1972)

7. Pyke, D.A., Cassar, J., Todd, J., Taylor, K.W.: Glucose tolerance and serum insulin in identical twins of diabetics. Brit. med. J. 1970 IV, $649-651$

8. Corasi, E., Luft, R.: Insulin response to glucose infusion in diabetic and nondiabetic monozygotic twin pairs. Genetic control of insulin response. Acta endocr. (Kbh.) 55, 330-345 (1967)

9. Coleman, D. L., Hummel, K.P.: Hyperinsulinemia in pre-weaning diabetes (db) mice. Diabetologia 10, $607-610(1974)$

10. Schmidt, F.L., Leslie, L.G., Schultz, J.R., Gerritsen, G.C.: Epidemiological studies of the Chinese hamster. Diabetologia 6, 154-157 (1970)

11. Folch, I., Lees, M., Sloan-Stanley, G.H.: A single method for the isolation and purification of total lipids from animal tissues. J. biol. Chem. 226, 497$509(1957)$
12. Natelson, S.: Microtechniques of clinical chemistry. Springfield, Ill. : C.C. Thomas 1961.

13. Snell, C.T., Snell, F.D.: Colorimetric methods of analysis, p. 184. Toronto: D. Van Wostrand 1945

14. Official Methods of Analysis of the Association of Official Analytical Chemists, 11th ed., (Horwitz, W., ed.) pp. 127-131. Washington, D.C., 1970

15. Riley, V.: Adaptation of orbital bleeding technique to rapid serial blood studies. Proc. Soc. exp. Biol. (N.Y.) 104, 751-754 (1960)

16. Blanks, M.C., Gerritsen, G.C.: An ultramicro assay for insulin. Proc. Soc. exp. Biol. (N. Y.) 146, 448-452 (1974)

17. Zaharko, D.S., Beck, L.V.: Studies of a simplified insulin immunoassay using cellulose powder. Diabetes 17, $444-457$ (1968)

18. Siegel, S.: Nonparametric statistics for the behavorial sciences, p. 75. New York: McGraw Hill 1956

19. Schedl, H.P., Wilson, H.D.: Effects of diabetes on intestinal growth and hexose transport in the rat. Amer. J. Physiol. 220, 1739-1745 (1971)

20. Olsen, W.A., Rosenberg, I. H. Intestinal transport of sugars and amino acids in diabetic rats. J. clin. Invest. 49, 96-105 (1970)

21. Vinnik, I.E., Kern, F., Jr., Sussman, K.E.: The effects of diabetes mellitus and insulin on glucose absorption by the small intestine in man. J. Lab. clin. Med. 66, 131-136 (1965)

22. Corsini, G., Gandolfi, E., Bonechi, I., Cerri, B.: Fat absorption in diabetes mellitus. Diabetes 16, 455-461 (1967)

23. Parkinson, T.M.: Enhanced intestinal fat absorption in diabetic Chinese hamsters. Diabetologia 9, 505-508 (1973)

24. Chang, A.Y., Schnieder, D.T.: Metabolic abnormalities in the pancreatic islets and livers of the diabetic Chinese hamster. Diabetologia 6, 180 - 185 (1970)

25. Seltzer, H.S.: Diabetes mellitus: Theory and practice. (Ellenberg, M., Rifkin, H., eds.) p. 445. New York: MeGraw Hill 1970

26. Grodsky, G.M., Frankel, B., Gerich, J., Gerritsen, G.C.: The diabetic chinese hamster: In vitro insulin and glucagon release; the "chemical diabetic"; and the effect of diet on ketonuria. Diabetologia 10, 521528 (1974)

27. Fajans, S.S., Conn, J.W.: The early recognition of diabetes mellitus. Ann. N.Y. Acad. Sci. 82, 208-218 (1959)

28. Porte, D. Jr., Graber, A.L., Kuzuya, T., Williams, R.H.: The effect of epinephrine on immunoreactive insulin levels in man, J. elin. Invest. 45, 228-236 (1966)

Dr. George C. Gerritsen

Diabetes and Atherosclerosis Research

The Upjohn Company

Kalamazoo, Michigan 49001

USA 